\title{
Time of Eclosion and Mating Success of Male Sagebrush Crickets
}

\section{Authors}

Scott K. Sakaluk, Geoffrey D. Owner, Colleen M. McGrath, Charles Collins, Jennifer Adams, Eric Bastien, Nathan Jarvis, Julia Tomasson, Livia Zihlmann, J. Chadwick Johnson, Rebecca Halpin, Gina Hupton, and W. Andrew Snedden 


\title{
TIME OF ECLOSION AND MATING SUCCESS OF MALE SAGEBRUSH CRICKETS
}

\author{
SCOTT K. SAKALUK $\downarrow$ GeOFFREy D. OWER $\downarrow$ COLLEEN M. MCGRATH \\ SCHOOL OF BIOLOGICAL SCIENCES ↔ ILLINOIS STATE UNIVERSITY $\uparrow$ NORMAL, IL \\ CHARLES COLLIS $\uparrow$ JENNIFER ADAMS $\uparrow$ ERIC BASTIEN $\uparrow$ NATHAN JARVIS \\ JULIA TOMASSON $\bullet$ LIVIA ZIHLMANN \\ CLAYTON HIGH SCHOOL $\uparrow$ CLAYTON, MO \\ J. CHADWICK JOHNSON $\downarrow$ REBECCA HALPIN $\downarrow$ GINA HUPTON \\ DiVISION OF MATHEMATICAL AND NATURAL SCIENCES $\uparrow$ ARIZONA STATE UNIVERSITY WEST \\ PHOENIX, AZ \\ W. ANDREW SNEDDEN $\uparrow$ VICTORIA $\uparrow$ BRITISH COLUMBIA
}

\begin{abstract}
$\uparrow \quad$ ABSTRACT
Few studies have measured multivariate sexual selection acting on the sexual signals of male insects in wild populations. Sagebrush crickets are ideally suited to such investigations because mating imposes an unambiguous phenotypic marker on males arising from nuptial feeding by females. However, an important assumption underlying such studies is that males collected as virgins and those collected as nonvirgins had equal opportunities to mate, an assumption that may be violated if males eclose (i.e. emerge following pupation) at different times of the breeding season. If mated males are those in the population that eclosed earlier and hence had a longer period to obtain matings than males in the virgin group, then differences in the songs of virgin and mated males could simply be an artifact of age-related changes in male morphology as opposed to a causal factor underlying variation in male mating success. Accordingly, we conducted a mark-recapture study to determine if there is an association between first appearance in the population and the likelihood of mating in free-living males. We captured all of the virgin males calling in the study population and marked them uniquely with a numbered tag. Subsequently, we tracked the mating success of 98
\end{abstract}

male subjects through the mid-point of the breeding season. There was no significant effect of date of capture (a proxy for time of eclosion) on time to mating. We conclude, therefore, that any differences in the songs of virgin and mated males stems from their effect on male mating success and not from any agerelated effects.

\section{$\downarrow \quad$ INTRODUCTION}

The sagebrush cricket, Cyphoderris strepitans (Orthoptera: Haglidae), is one of only three extant species of hump-winged grigs in North America, relatively obscure ensiferans that are restricted to mountainous areas of western North America (Morris and Gwynne 1978; Kumala et al. 2005). C. strepitans occurs in high-elevation sagebrush meadows nestled within coniferous forests in Wyoming and Colorado. In Grand Teton National Park, where the majority of field studies of $C$. strepitans have been conducted (Sakaluk and Ivy 1999; Sakaluk et al. 2004; Leman et al. 2009), sexual activity commences in mid-May. Each night of the breeding season, males emerge from the ground cover to secure a calling perch in sagebrush or lodgepole pine, where they sing to attract sexually receptive 
females (Snedden and Sakaluk 1992; Snedden and Irazuzta 1994). Copulation is initiated when a female climbs onto the dorsum of the male, and ends with the transfer of a spermatophore to the female. During copulation, the female feeds on the male's fleshy hind wings and ingests hemolymph seeping from the wounds she inflicts (Morris 1979; Eggert and Sakaluk 1994). The wing-feeding behavior of females provides us with a powerful tool for documenting male mating success because the mating status of males can easily be determined by examining their hind wings for the melanized scars resulting from mating.

Over the past two years, we have used wingwounding as a bivariate measure of male fitness (intact wings $=$ virgin, wounded $=$ mated $)$ in studies designed to measure sexual selection in free-living crickets. Specifically, we have attempted to identify the morphological and acoustical traits that are the targets of sexual selection by collecting an equal number of virgin and non-virgin males at the midpoint of the breeding season, recording their songs, and preserving them for subsequent morphological analysis. Preliminary analyses have revealed stabilizing selection on male carrier frequency and strong directional selection for longer pulse durations and hence, greater energy expenditure (Ower et al., in review).

The selection analyses described above assume that males in the virgin and mated groups had equal opportunities to mate, an assumption that may be violated if males eclosed at different times of the breeding season. If mated males are those in the population that eclosed earlier and hence had a longer period to obtain matings than males in the virgin group, then differences in the songs of virgin and mated males could simply be an artifact of age-related changes in male morphology as opposed to a causal factor underlying variation in male mating success. Accordingly, we conducted a mark-recapture study in 2012 to determine if there is an association between first appearance in the population and the likelihood of mating in free-living males.

\section{$\uparrow \quad$ MeThODS}

At the beginning of the breeding season, we established a study plot in Grand Teton National Park near the border with Bridger-Teton National Forest $\left(43^{\circ} 54^{\prime} 40.56^{\prime \prime} \mathrm{N}, 110^{\circ} 28^{\prime} 20.24^{\prime \prime} \mathrm{W}\right)$. This population was chosen because no males had mated at our first population census. On four of the first five days of the study, we attempted to capture all of the virgin males calling in the study area and any mated males that had been previously marked. Each male was marked with a numbered tag secured to his pronotum with cyanoacrylic glue. Fluorescent paint was also applied around the pronotum and to the femora to facilitate the recapture of marked individuals with portable fluorescent lanterns. Seven days after the population was first censused, the population attained a ratio of approximately $1: 1$ virgin to mated males, at which time the study was terminated. We recorded data on the date of initial capture and mating success for 98 males initially marked as virgins. We used failure-time analysis to examine the effect of a male's capture date on his time to mating (Allison 1995), specifically, a Cox regression as implemented by PROC PHREG in SAS (version 9.2, SAS Institute Inc. 2010). The EXACT option was specified in the model statement to handle ties, instances in which different males had the same time to mating. This option was employed because it assumes that mating times are, in reality, continuous and ordered, assumptions that are almost certainly met by our data.

\section{$\downarrow \quad$ RESULTS}

Our analysis revealed no significant effect of date of capture on time to mating (Wald $\chi^{2}=0.32, P=$ $0.57)$. We also compared virgin $(N=55)$ and mated males $(N=43)$ with respect to their date of capture. Mated males were first captured significantly earlier than virgin males (Student's $t$ test with equal variances, $t_{96}=2.07, P=0.042$ ), but the difference in the time of their initial appearance in the population was less than half a day $((0.49 \pm 0.24$ days (mean \pm $\mathrm{SE})$ ).

\section{$\uparrow \quad$ DISCUSSION}

Few studies have measured multivariate sexual selection acting on the sexual signals of male insects (Brooks et al. 2005; Bentsen et al. 2006; Gershman et al. 2012), and almost none in wild populations (Punzalan et al. 2010). The dearth of studies in wild populations is almost certainly a consequence of the difficulty in measuring male mating success under natural conditions. Although this difficulty can be circumvented by broadcast of experimentally manipulated male sexual signals to females in natural populations (Bentsen et al. 2006) or by intensive long-term video recordings (RodríguezMuñoz et al. 2010), such studies are the exception rather than the rule. Sagebrush crickets, Cyphoderris strepitans (Orthoptera: Haglidae), offer an excellent model system with which to pursue measurements of 
multivariate selection in wild populations because mating imposes an unambiguous phenotypic marker on males that results from an unusual form of nuptial feeding by females (Morris 1979; Eggert and Sakaluk 1994).

An earlier study, in which males were experimentally muted and returned to their natural population, revealed that song is essential to male mating success (Snedden and Sakaluk 1992). More recent work has quantified sexual selection operating on male song by recording songs of virgin and mated males captured from wild populations (Ower et al., in review). This works has revealed a complex pattern of multivariate nonlinear selection characterized primarily by strong stabilizing and disruptive selection on male song traits. However, an important assumption underlying these studies is that males collected as virgins and those collected as non-virgins had equal opportunities to mate, an assumption that may be violated if males eclose at different times of the breeding season. The present study shows no significant effect of date of capture (a proxy for time of eclosion) on time to mating. We conclude, therefore, that any differences in the songs of virgin and mated males stems from their effect on male mating success and not from any age-related effects.

\section{ACKNOWLEDGEMENTS}

This work was supported by grants from the National Science Foundation to S.K.S. (IOS-0718140 and IOS-1118160) including Research Experiences for Undergraduates, Research Experiences for Teachers, and Research Associate supplemental awards.

\section{$\uparrow \quad$ LiTERATURE CITED}

Allison D. 1995. Survival Analysis Using the SAS System: A Practical Guide. Cary, North Carolina, SAS Institute.

Bentsen C, Hunt J, Jennions MD, Brooks R. Complex multivariate sexual selection on male acoustic signaling in a wild population of Teleogryllus commodus. American Naturalist 167:E102-E116.

Brooks R, Hunt J, Blows MW, Smith MJ, Bussière LF, Jennions MD. 2005. Experimental evidence for multivariate stabilizing sexual selection. Evolution 59:871-880.
Eggert A-K, Sakaluk SK. 1994. Sexual cannibalism and its relation to male mating success in sagebrush crickets, Cyphoderris strepitans (Orthoptera: Haglidae). Animal Behaviour 47:1171-1177.

Gershman SN, Mitchell C, Sakaluk SK, Hunt J. 2012. Biting off more than you can chew: sexual selection on the free amino acid composition of the spermatophylax in decorated crickets. Proceedings of the Royal Society B 279:2531-2538.

Kumala M, McLennan DA, Brooks DR, Mason AC. 2005. Phylogenetic relationships within Hump-Winged Grigs, Cyphoderris (Insecta, Orthoptera, Tettigonioidea, Haglidae). Canadian Journal of Zoology 83:1003-1011.

Leman JC, Weddle CB, Gershman SN, Kerr AM, Ower GD, St John JM, Vogel LA, Sakaluk SK. 2009. Lovesick: immunological costs of mating to male sagebrush crickets. Journal of Evolutionary Biology 22:163-171.

Morris GK. 1979. Mating systems, paternal investment and aggressive behavior of acoustic Orthoptera. Florida Entomologist 62: 9-17.

Morris GK, Gwynne DT. 1978. Geographic distribution and biological observations of Cyphoderris (Orthoptera: Haglidae) with a description of a new species. Psyche 85: 147167.

Ower GD, Judge KA, Steiger S, Caron KJ, Smith RA, Hunt J, Sakaluk SK. provisionally accepted. Multivariate sexual selection on male song structure in wild populations of sagebrush crickets, Cyphoderris strepitans (Orthoptera: Haglidae). Ecology and Evolution.

Punzalan D, Rodd FH. Rowe L. 2010. Temporarily variable multivariate sexual selection one sexually dimorphic traits in a wild insect population, American Naturalist. 175: 401414.

Rodríguez-Muñoz R, Bretman A, Slate J, Walling CA, Tregenza T. 2010. Natural and sexual selection in a wild insect population. Science 328:1269-1272.

Sakaluk SK, Campbell MTH, Clark AP, Johnson JC, Keorpes PA. 2004. Hemolymph loss during nuptial feeding constrains male mating 
success in sagebrush crickets. Behavioral Ecology 15:845-849.

Sakaluk SK, Ivy TM. 1999. Virgin-male mating advantage in sagebrush crickets: differential male competitiveness or non-independent female mate choice? Behaviour 10:13351346.
Snedden WA, Irazuzta S. 1994. Attraction of female sagebrush crickets to male song: the importance of field bioassays. Journal of Insect Behavior 7:233-236.

Snedden WA, Sakaluk WA. 1992. Acoustic signaling and its relation to male mating success in sagebrush crickets. Animal Behaviour 44:633-639. 